\title{
STUDI KELAYAKAN PENGGUNAAN MESIN DIESEL DENGAN METODE BREAK EVEN POINT (BEP) DAN ANALISIS SENSITIVITAS PADA PLTD (Studi Kasus : PT PLN Persero Sektor Pembangkitan Lombok PLTD Ampenan)
}

\author{
Made Wijana*, A.A. Alit Triadi, Lalu Syahrul Anwar \\ Teknik Mesin, Fakultas Teknik, Universitas Mataram, JI. Majapahit No. 62, Mataram \\ *Email: wijanamd23@yahoo.co.id
}

\begin{abstract}
This study intended to analyze the feasibility of the use of the Power Plant (PLTD) of Ampenan using the break even point (BEP) and sensitivity analysis. That there are several alternatives that can be taken are: first, if the use of the selling price to the public's ability to Rp. 800 per kWh and a subsidy of Rp. 29.758.612.278 per month, then power plant will have a turnover in the month to 12 to earn a revenue of $R p$. 159.148.857.478. Secondly, if the use of the selling price to Rp. 900 per kWh and a subsidy of Rp. 28.100.809.978 per month, then power plant will have a turnover in the month to 12 to earn a revenue of $R p .179 .042 .464 .663$. Thirdly, if the use of the selling price to Rp. 1000 per kWh and a subsidy of Rp. 26.443.007.678 per month, then power plant will have a turnover in the month to 12 to earn a revenue of Rp. 199.936.071.847. Then the results of research using sensitivity analysis to changes in the initial investment is known that the increase in initial investment $600,83 \%$ below power plant is still feasible to operate.. But the power plant would not be feasible to operate when the increase $600,83 \%$ above the initial investment. Furthermore the sensitivity analysis to changes in income are known to decrease in revenue of less than $85,73 \%$ of power plant is still worth operating. But if the decline in revenue was down more than $85,73 \%$ power plant operation is not feasible.
\end{abstract}

Keywords: Power plant, Diesel engine, break even point, sensitivity analysis

\section{PENDAHULUAN}

Keberadaan energi listrik menjadi sangat penting demi terselenggaranya pembangunan nasional baik secara langsung maupun tidak langsung. Energi listrik harus tercukupi karena sangat penting bagi seluruh masyarakat. Dalam pemenuhan kebutuhan energi listrik diseluruh Indonesia, Negara telah mengaturnya pada Pasal 33 ayat (2) UUD Negara Indonesia Tahun 1945 yang menyatakan bahwa usaha penyediaan tenaga listrik dikuasai oleh negara dan dipergunakan untuk kemakmuran rakyat yang penyelenggaranya dilakukan oleh pemerintah dan pemerintah daerah. Untuk mendukung usaha tersebut, maka pemerintah memberi wewenang penuh kepada PT. Perusahaan Listrik Negara (Persero) untuk menyediakan dan mengatur distribusi listrik ke seluruh wilayah Indonesia guna mendukung pertumbuhan ekonomi sesuai dengan Undang-Undang No.15 tahun 1985. Tetapi pada kenyataannya PT. PLN masih kesulitan untuk memenuhi kebutuhan energi listrik di Indonesia (Patricia, 2012).

Sebagai bentuk komitmen PT. PLN (Persero) guna peningkatan pelayanan dan mengantipasi perkembangan listrik di Nusa Tenggara Barat (NTB). PT. PLN (Persero)
Wilayah NTB Sektor Pembangkitan Lombok adalah salah unit bisnis dari PT. PLN (Persero) yang berkedudukan di Mataram, dibentuk berdasarkan surat keputusan Direksi PT.PLN (Persero) No.087.K/010/2002 tanggal 25 Juni 2002, sebagai unit pelaksana dan penanganan khusus bidang pembangkitan yang bertanggung jawab untuk memproduksi kWh sesuai dengan kebutuhan listrik di Pulau Lombok. Pembangkit Listrik Tenaga Diesel (PLTD) Ampenan, dalam hubungan kerja merupakan bagian dari PT PLN (Persero) wilayah NTB. Berdiri pada tahun 1986 yang berlokasi di Tanjung Karang, Sebagai bentuk komitmen PT. PLN (Persero) guna peningkatan pelayanan dan mengantipasi perkembangan listrik di Nusa Tenggara Barat (NTB). Berdasarkan studi awal yang penulis lakukan di PLN NTB diperoleh informasi bahwa PLN NTB belum pernah melakukan studi atau analisa yang berkaitan dengan usahanya. Analisa kelayakan kegiatan usaha sangat perlu untuk dilakukan, mengingat umur mesin pembangkit listrik umurnya bervariasi. Beberapa metode yang dapat digunakan untuk melakukan analisa kelayakan usaha seperti Analisis Break Even Point (BEP), Net Benefit Cost Ratio (Net B/C), Net Present Value (NPV), Internal Rate of Retrun (IRR), 
External Factor Evaluation (EFE), Internal Factor Evaluation (IFE) dan analisis SWOT. Analisis Break Break Even Point (BEP) adalah analisis yang paling sederhana dibandingkan dengan analisis yang lain seperti Net Benefit Cost Ratio (Net B/C), Net Present Value (NPV), Internal Rate of Retrun (IRR), External Factor Evaluation (EFE), Internal Factor Evaluation (IFE) dan analisis SWOT.

Penelitian-penelitian yang berkaitan dengan BEP telah banyak dilakukan seperti yang pernah dilakukan oleh (Himayati, 2010), (Febriyandi, 2012), dan (Kholiq, 2015). Namun dari penelitian yang terdahulu tersebut tidak dilengkapi dengan analisis sensitivitas. Oleh sebab itu, penulis menambahkan dengan analisis sensitivitas yang dapat menghitung dan memprediksi bagaimana keadaan perusahaan apabila suatu waktu ada nilai atau biaya yang tidak menentu. Dan kita ketahui bahwa sekarang ini harga bahan bakar diesel yaitu solar mengalami kenaikan dan penurunan atau harganya tidak menentu .

\section{TINJAUAN PUSTAKA \\ Pengertian Pembangkit Listrik Tenaga Diesel}

Pembangkit Listrik Tenaga Diesel (PLTD) ialah Pembangkit listrik yang menggunakan mesin diesel sebagai penggerak mula (prime mover).Prime mover merupakan peralatan yang mempunyai fungsi menghasilkan energi mekanis yang diperlukan untuk memutar rotor generator.Mesin diesel sebagai penggerak mula PLTD berfungsi menghasilkan tenaga mekanis yang dipergunakan untuk memutar rotor generator. Pada mesin Diesel Energi Bahan bakar diubah menjadi energi mekanik dengan proses pembakaran di dalam mesin itu sendiri. Yang dimaksud dengan Unit PLTD adalah kesatuan peralatan-peralatan utama dan alat-alat bantu serta perlengkapannya yang tersusun dalam hubungan kerja, membentuk sistem untuk mengubah energi yang terkandung didalam bahan bakar minyak menjadi tenaga mekanis dengan menggunakan mesin diesel sebagai penggerak utamanya dan seterusnya tenaga mekanis tersebut oleh generator diubah menjadi tenaga listrik.

\section{Mesin Diesel}

Mesin diesel termasuk mesin dengan pembakaran dalam atau disebut dengan motor bakar ditinjau dari cara memperoleh energi termalnya. Untuk membangkitkan listrik sebuah generator menggunakan generator dengan sistem penggerak tenaga diesel atau yang biasa dikenal dengan sebutan genset (Generator Set ).

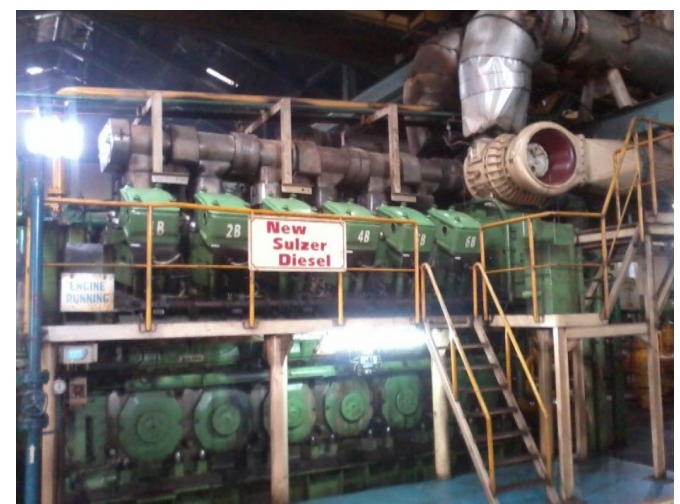

Gambar 1. Mesin Diesel New Sulzer

\section{Definisi Studi Kelayakan}

Kelayakan adalah suatu peluang usaha baru atau modifikasi usaha untuk menjamin agar pengeluaran modal mencapai tujuan yang diharapkan, atau dengan kata lain suatu penelitian tentang layak atau tidaknya suatu proyek bisnis yang biasanya merupakan proyek investasi itu dilaksanakan. Maksud layak atau tidak layak disini adalah prakiraan bahwa bisnis akan dapat atau tidak mendapatkan keuntungan yang layak bila telah dioperasikan (Komarudin, 2012).

Menurut Yacob Ibrahim (2003) studi kelayakan bisnis adalah kegiatan untuk memulai sejauh mana manfaat yang dapat diperoleh dalam melaksanakan suatu kegiatan usaha/ proyek. Studi kelayakan yang juga sering disebut dengan feasibility study merupakan bahan pertimbangan dalam mengambil keputusan, apakah menerima atau menolak dari suatu gagasan usaha/proyek yang direncanakan.

Menurut Husnan dan Suwarsono (1999) tujuan dilaksanakannya studi kelayakan adalah untuk menghindari keberlanjutan modal yang terlalu besar untuk kegiatan yang ternyata tidak menguntungkan.

Studi kelayakan yang dimaksud dalam penelitian ini adalah studi kelayakan penggunaan mesin diesel pada PLTD Ampenan dengan metode Break Even Point dan analisis sensitivitas.

\section{Pengertian Analisis Break Even Point}

Break Event Point atau titik impas sampai saat ini belum bisa diterjemahkan ke dalam bahasa Indonesia secara pasti. Hal ini dikarenakan belum adanya kesepakatan tentang pengertian Break Even Point oleh 
para pakar ekonomi. Oleh karena itu karena masih adanya perbedaan-perbedaan tentang pengertian Break Even Point, maka berikut ini beberapa definisi Break Even Point menurut pakar-pakar ekonomi dalam literaturnya.

Menurut Pujawan (2002) dalam bukunya yang berjudul "Ekonomi Teknik" Analisis break even point adalah salah satu analisis dalam ekonomi teknik yang sangat popular digunakan terutama pada sektorsektor industri yang padat karya. Analisis ini akan berguna apabila seorang akan mengambil keputusan pemilihan alternatif yang cukup sensitif terhadap parameter atau variabel dan bila variabel-variabel tersebut sulit diestimasi nilainya.

Menurut Sigit (1990) dalam bukunya yang berjudul "Analisis Break Even" Analisis break even point adalah " perhitungan rugilaba dari suatu periode kerja atau dari suatu kegiatan usaha tertentu, perusahaan itu tidak memperoleh laba, tetapi juga tidak menderita kerugian".

Menurut Halim dan Bambang (1990) dalam bukunya yang berjudul "Akuntansi Manajemen" Analisis break even point adalah "titik di mana jumlah penghasilan perusahaan sama besarnya dengan jumlah biaya perusahaan.

Menentukan Break Even Point (Titik Impas) Analisis break even point adalah analisis yang digunakan untuk mengukur tingkat keseimbangan antara biaya, volume dan penjualan agar perusahaan tidak mengalami untung maupun rugi.

Alat analisis yang dapat digunakan dalam mencari tingkat break even point adalah:

1. Pendekatan matematika

$$
B E P(X)=\frac{F C}{p-c}
$$

Dimana:

$$
\begin{array}{ll}
\mathrm{BEP}(\mathrm{X}) & =\text { Break event point dalam unit } \\
\mathrm{FC} & =\text { Fixed Cost }(\mathrm{Rp}) \\
\mathrm{p} & =\text { Price }(\mathrm{Rp} / \text { Unit }) \\
\mathrm{C} & =\text { Cost }
\end{array}
$$

$$
B E P(p . X)=\frac{F C}{1-\frac{c}{p}}
$$

Di mana:

$$
\begin{array}{ll}
\operatorname{BEP}(\mathrm{p} . \mathrm{X}) & =\text { Break even point dalam Rp. } \\
\mathrm{FC} & =\text { Fixed Cost }(\mathrm{Rp}) \\
\mathrm{VC} & =\text { Variabel Cost }(\mathrm{Rp}) \\
\mathrm{X} & =\text { Volume produksi (unit) } \\
\mathrm{p} & =\text { Price (Rp/Unit) } \\
\mathrm{C} & =\text { Cost (Rp/Unit) }
\end{array}
$$

\section{Dengan cara grafik}

Secara grafik, titik break even point ditentukan oleh persilangan antara garis total revenue dan garis total cost seperti gambar 2 .

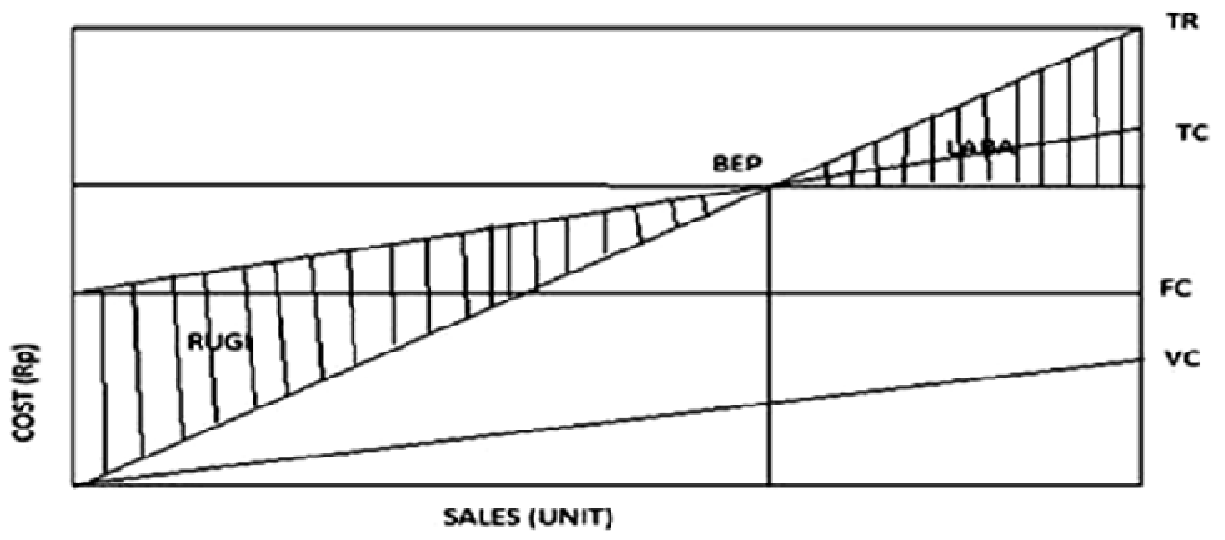

Gambar 2. Analisis break even point dengan menggunakan grafik

\section{Analisis Sensitivitas}

Untuk mengetahui seberapa sensitif suatu keputusan terhadap perubahan nilainilai investasi yang mempengaruhinya, maka setiap pengambilan keputusan pada ekonomi teknik hendaknya disertai dengan analisis sensitivitas. Analisis sensitivitas ini akan memberikan gambaran sejauh mana suatu keputusan akan cukup kuat berhadapan dengan perubahan faktor-faktor atau nilai-nilai investasi yang mempengaruhinya (Pujawan, 2002).

Analisis sensitivitas dilakukan untuk mengantisipasi kemungkinan-kemungkinan yang terjadi agar bisa diambil langkahlangkah yang tepat untuk dapat menyelesaikan permasalahan yang mungkin terjadi dan menjamin bahwa setiap rencana investasi aman untuk dilaksanakan. Pemodelan pertama dilakukan 
dengan mengasumsikan bahwa semua komponen biaya mengalami kenaikan dengan angka pendekatan sebesar 10\% sedangkan pendapatannya tetap. Pemodelan kedua dilakukan dengan mengasumsikan bahwa semua komponen pendapatan mengalami penurunan dengan angka pendekatan sebesar $10 \%$ sedangkan biaya-biaya yang dikeluarkan tetap (Nadiasa dkk, 2010).

Analisis sensitivitas digunakan untuk melihat dampak suatu perubahan keadaan pada hasil analisis kelayakan. Analisis ini bertujuan untuk menilai hasil analisis kelayakan investasi apabila terjadi perubahan pada perhitungan biaya atau manfaat. Dari hasil analisis tersebut akan terlihat apakah kelayakan suatu investasi sensitif terhadap perubahan (Ariesa dan Tinaprilla, 2012).

\section{Menentukan Analisis Sensitivitas}

Langkah pertama yang akan kita lakukan adalah menentukan keputusan awal (sebelum melakukan analisis sensitivitas) dari alternatif tersebut dengan cara menghitung nilai awal nettonya (NPW). NPW adalah nilai sekarang dari suatu jumlah uang periode mendatang. Cara yang digunakan mencari NPW adalah :

Pendekatan matematika, Pujawan (2002)

$N P W=P+A(P / A, i \%, n)$

Dimana :

$\mathrm{NPW}=$ Net present worth

$\mathrm{P} \quad=$ Total dana awal investasi

A $=$ Pendapatan perbulan

$\mathrm{i} \quad=$ Tingkat suku bunga (\%)

$\mathrm{n} \quad=$ Lama investasi $(0,1,2 \ldots \mathrm{n})$

Dalam metode NPW terdapat tiga

kriteria investasi, yaitu :

1. $N P W>0$, artinya secara finansial usaha tersebut layak dilakukan Karena manfaat yang diperoleh lebih besar dari biaya yang dikeluarkan.

2. $N P W=0$, artinya secara finansial usaha tersebut sulit dilakukan Karena manfaat yang diperoleh hanya cukup untuk menutupi biaya yang dikeluarkan.

3. $N P W<0$, artinya secara finansial usaha tersebut tidak layak dilakukan Karena manfaat yang diperoleh lebih kecil dari biaya yang dikeluarkan.

\section{METODE PENELITIAN}

Penelitian ini menggunakan metode deskriptif yaitu suatu metode dalam meneliti status sekelompok manusia, suatu objek, suatu set kondisi, suatu sistem pemikiran ataupun suatu kelas peristiwa pada masa sekarang. Penggunaan jenis penelitian ini didasarkan pada masalah yang dihadapi yaitu berusaha menampilkan gambaran, menganalisis dalam menarik kesimpulan tentang kelayakan usaha dari bisnis tersebut Tahapan dari penelitian diperlihatkan pada gambar 3.

\section{Teknik Pengambilan dan Analisa Data}

Data yang digunakan dalam penelitian ini adalah data primer dan sekunder. Data primer diperoleh langsung dari objek yang diteliti dan biasanya masih belum mengalami pengolahan lebih lanjut. Data primer diperoleh melalui pengamatan langsung dan wawancara dengan bagian keungan dan akuntansi PLTD Ampenan Bapak Aries dwi Rachmanto. Data sekunder dapat diperoleh dari perpustakaan UNRAM, studi literatur dari buku, internet, dan penelitian sebelumnya.Dalam menganalisis data digunakan analisis kuantitatif yaitu penulis akan melakukan pengumpulan data berupa angka yang dibutuhkan sehubungan dengan masalah yanag akan diteliti, sehingga hasil penelitian dapat lebih dipercaya dan dapat diandalkan kebenarannya. Untuk analisis kuantitatif digunakan rumus Break Even Point dan analisis sensitivitas.

\section{HASIL DAN PEMBAHASAN \\ Analisis Biaya Penggunaan Mesin Diesel Pada PLTD Ampenan}

Biaya dalam penggunaan mesin diesel untuk memenuhi kebutuhan listrik masyarakat Lombok terdiri dari biaya tetap dan biaya variabel. Dalam penelitian ini yang termasuk biaya tetap adalah aset tanah, biaya penyusutan instalasi mesin, biaya penyusutan gedung, penyusutan perlengkapan penyaluran tenaga listrik, penyusutan perlengkapan umum, dan biaya beban SDM seperti (gaji karyawan, tunjangan, iuran pemberi kerja, pajak penghasilan pasal 21 (PPh 21), perjalanan dinas, pemeliharaan kesejahteraan, SBO (spiritual, budaya, dan olahraga). Adapun yang termasuk biaya variabel dalah biaya operasional (pemakaian bahan bakar, pemakaian minyak pelumas, biaya ongkos angkut bahan bakar), biaya beban pemakaian material terdiri dari (beban pemakaian material transformator, beban pemakaian material kabel, beban pemakaian material alat ukur, beban pemakaian material perdsediaan umum, beban pemakaian material instalasi dan mesin, beban pemakaian material minyak dan pelumas), 
biaya beban jasa borong terdiri dari (beban jasa borong dan kelengkapan umum, beban jasa borong saluran air, beban jasa borong instalasi dan mesin, beban jasa borong perlengkapan tenaga listrik, beban jasa borong perlengkapan pengolahan data, beban jasa borong perlengkapan telekomunikasi, beban jasa borong perlengkapan umum, beban jasa borong perlengkapan kendaraan bermotor dan mobil), dan biaya administrasi dan umum terdiri dari (pemakaian perkakas dan peralatan, perjalanan dinas dan diklat, teknologi informasi, listrik gas dan air, pos dan telekomunikasi, beban Bank, bahan makanan dan konsumsi, sewa fotocopy dan kelengkapannya, ATK (alat tulis kantor), barang cetakan dan penerbitan, dan iklan).

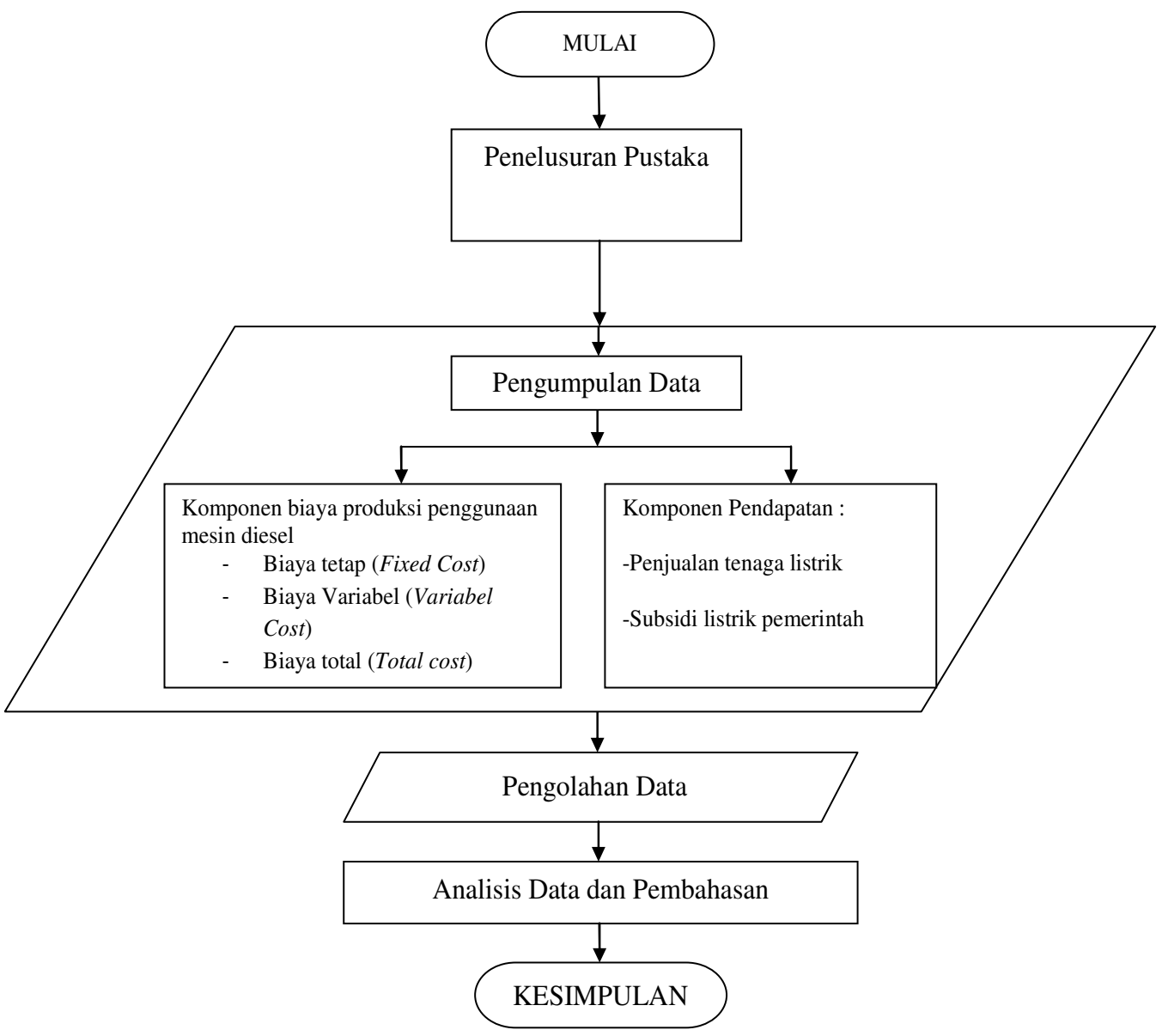

Gambar 3. Diagram alir penelitian

Analisis Pendapatan Penggunaan Mesin Diesel Dengan Menggunakan Harga Jual Ekonomis sebesar Rp 2.595,064

Dari analisis dapat diketahui bahwa harga keekonomisan adalah sebesar Rp 2.595,064 dengan penggunaan harga jual ekonomis $\mathrm{Rp} 2.595,064$ per kWh PLTD mengalami break even point setelah membangkitkan daya sebesar 198.476.846 $\mathrm{kWh}$ atau memperoleh pendapatan sebesar Rp 515.060.118.738, begitu juga dengan cara grafik gambar 4.1 , didapatkan titik pertemuan antara total reveneu dengan total cost berada pada tahun pertama yaitu bulan ke 12 tahun 2014. Pada titik ini PLTD Ampenan tidak mengalami keuntungan dan juga tidak mengalami kerugian, oleh karena itu dengan menggunakan harga jual ekonomis PLTD layak untuk dioperasikan.

Berdasarkan perhitungan didapatkan grafik break even point dalam penjualan listrik seperti pada gambar 4 . 


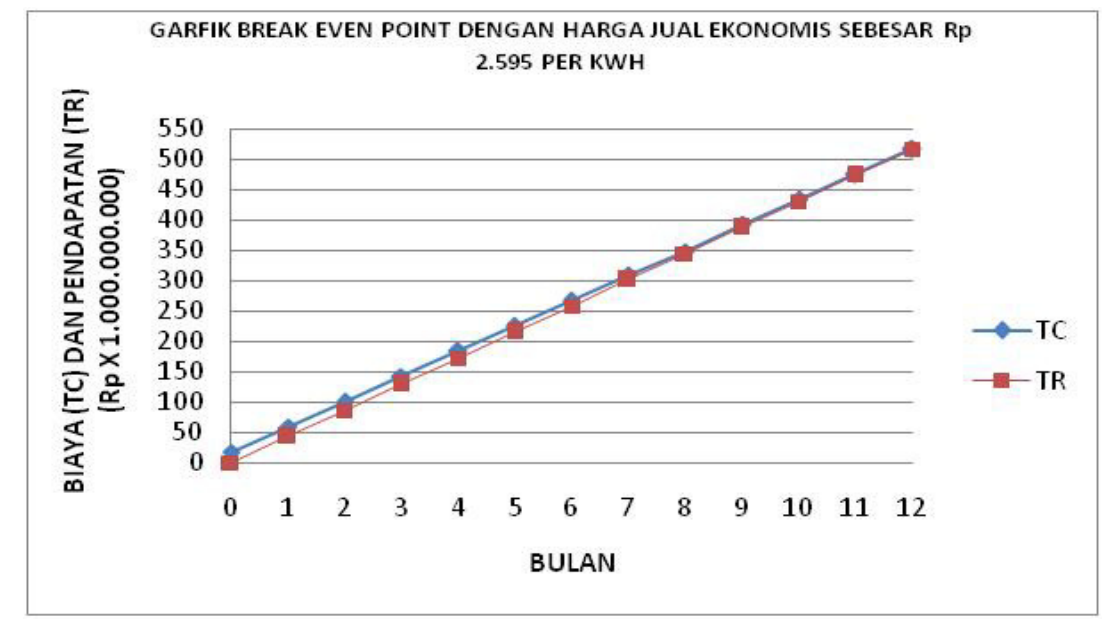

Gambar 4. Break even point penggunaan mesin diesel dengan harga jual ekonomis Rp. 2.595,064 per kWh

\section{Analisis Pendapatan Penggunaan Mesin Diesel Dengan Menggunakan Harga Jual Rp 800 per kWh}

Dengan penggunaan harga jual Rp. 800 per kWh didapatkan subsidi Rp. 29.758.612.278 perbulan. Maka dengan harga jual Rp 800 per kWh PLTD mengalami break even point setelah membangkitkan daya sebesar 198.936.072 kWh atau memperoleh pendapatan sebesar Rp. 159.148.857.478, begitu juga dengan cara grafik gambar 5, didapatkan titik pertemuan antara total reveneu dengan total cost berada pada tahun pertama yaitu bulan ke 12 tahun 2014.

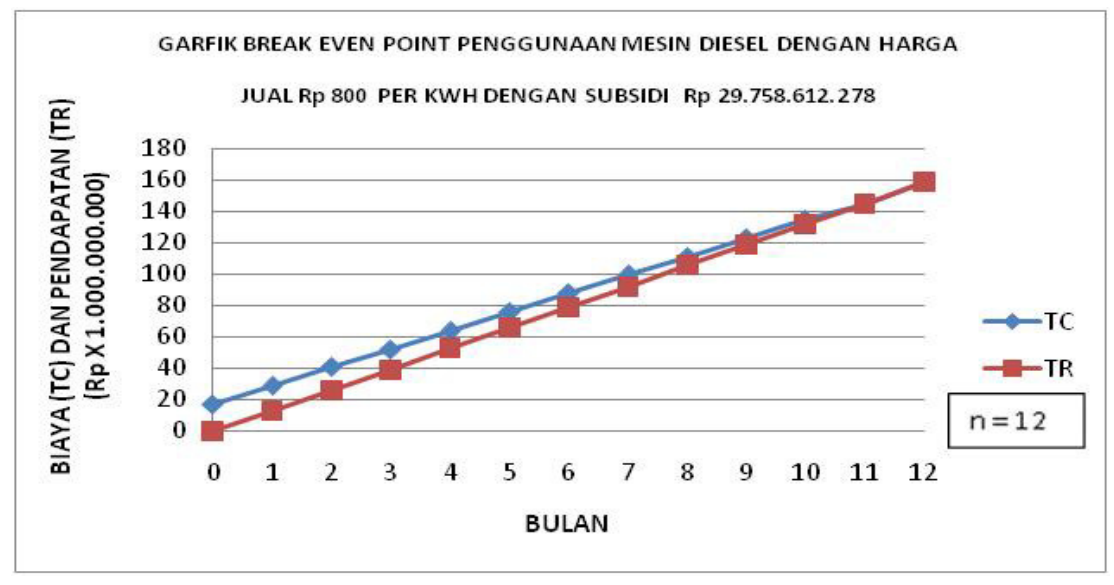

Gambar 5. Break even point penggunaan mesin diesel dengan harga jual ekonomis Rp. 800 per kWh

Pada titik ini PLTD Ampenan tidak mengalami keuntungan dan juga tidak mengalami kerugian, oleh karena itu dengan menggunakan harga jual Rp 800 dan subsidi Rp. 29.758.612.278 perbulan PLTD layak untuk dioperasikan.Berdasarkan perhitungan didapatkan grafik break even point dalam penjualan listrik seperti pada gambar 5 .
Analisis Pendapatan Penggunaan Mesin Diesel Dengan Menggunakan Harga Jual Rp 900 per kWh

Dengan penggunaan harga jual Rp. 900 per kWh didapatkan subsidi Rp. 28.100.809.978 perbulan. Maka dengan haraga jual Rp. 900 per kWh PLTD mengalami break even point setelah membangkitkan daya sebesar 198.936.072 $\mathrm{kWh}$ atau memperoleh pendapatan sebesar Rp. 179.042.464.663, begitu juga dengan 
cara grafik gambar 6, didapatkan titik pertemuan antara total reveneu dengan total cost berada pada tahun pertama yaitu bulan ke 12 tahun 2014. Pada titik ini PLTD Ampenan tidak mengalami keuntungan dan juga tidak mengalami kerugian, oleh karena itu dengan menggunakan harga jual $\mathrm{Rp} 900$ dan subsidi Rp. 28.100.809.978 perbulan PLTD layak untuk dioperasikan.

Berdasarkan perhitungan didapatkan grafik break even point dalam penjualan listrik seperti pada gambar 6 .

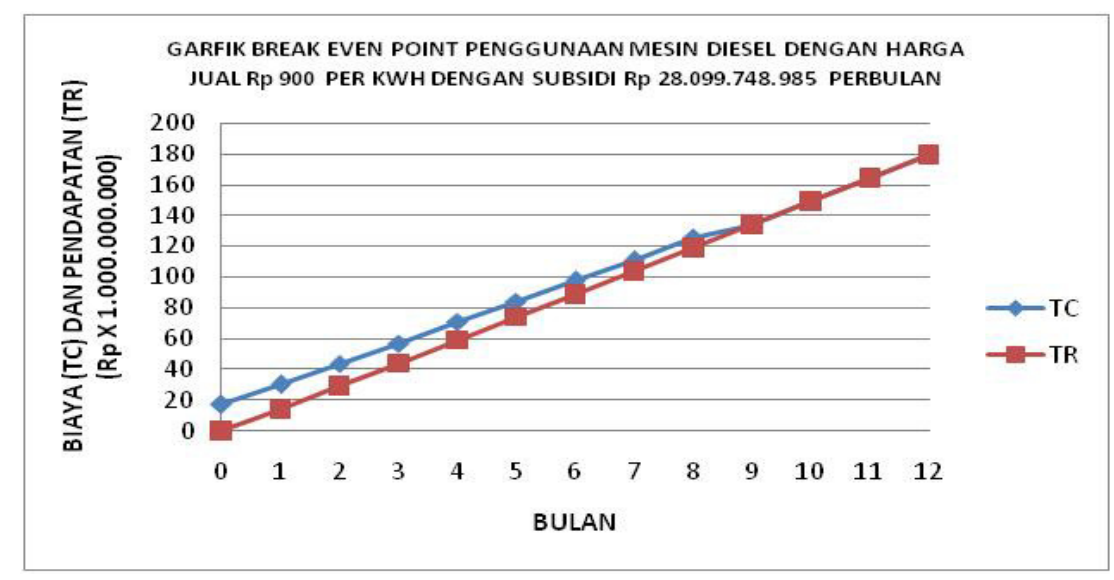

Gambar 6. Break even point penggunaan mesin diesel dengan harga jual ekonomis Rp. 900 per kWh

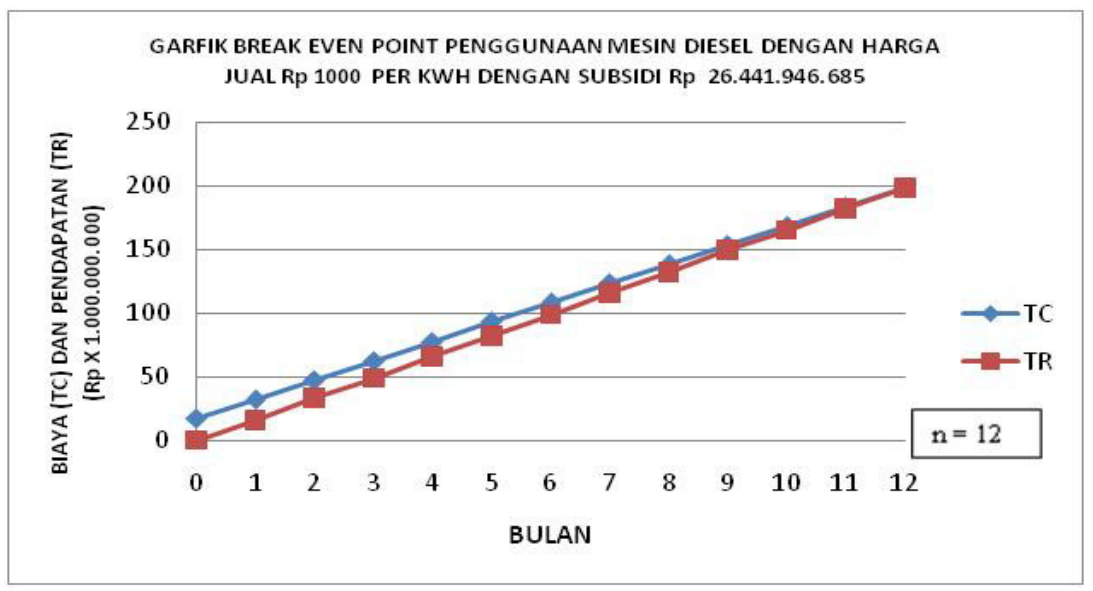

Gambar 7. Break even point penggunaan mesin diesel dengan harga jual ekonomis Rp. 1000 per kWh

\section{Analisis Pendapatan Penggunaan Mesin Diesel Dengan Menggunakan Harga Jual Rp 1000 per kWh}

Dengan penggunaan harga jual $R p$ 1000 per kWh didapatkan subsidi Rp 26.443.007.678 perbulan. Maka dengan haraga jual $\mathrm{Rp} 1000$ per kWh PLTD mengalami break even point setelah membangkitkan daya sebesar 198.936.072 $\mathrm{kWh}$ atau memperoleh pendapatan sebesar Rp. 198.936.071.847, begitu juga dengan cara grafik gambar 7 , didapatkan titik pertemuan antara total reveneu dengan total cost berada pada tahun pertama yaitu bulan ke 12 tahun 2014. Pada titik ini PLTD Ampenan tidak mengalami keuntungan dan juga tidak mengalami kerugian, oleh karena itu dengan menggunakan harga jual Rp 1000 dan subsidi Rp. 26.443.007.678 perbulan PLTD layak untuk dioperasikan.

Berdasarkan perhitungan didapatkan grafik break even point dalam penjualan listrik seperti pada gambar 7 . 
Analisis sensitivitas

Analisis sensitivitas dengan perubahan nilai investasi awal

Alternatif tersebut akan menjadi tidak layak bila perubahan nilai investasi awal menyebabkan nilai NPW berubah menjadi lebih kecil dari nol. NPW akan sama dengan nol bila besarnya investasi adalah : Bila investasi awal bertambah

$$
\begin{aligned}
600,8340525 \%,\left(\frac{620,8340525}{100}+1\right)=7,0083 \% \\
\text { Maka didapatkan nilai } \\
\begin{aligned}
\mathrm{P}= & -17.478 .664 .995 \times 7,0083 \\
= & -122.496 .436 .215 \\
\mathrm{NPW}= & \mathrm{P}+\mathrm{A}(\mathrm{P} / \mathrm{A}, \mathrm{i} \%, \mathrm{n}) \\
= & -122.496 .436 .215+1.456 .556 .911 \\
& (\mathrm{P} / \mathrm{A}, 0,6283 \%, 120) \\
= & -122.496 .436 .215+1.456 .556 .911 \\
& (84,10) \\
= & -122.496 .436 .215+122.496 .436 .215 \\
= & R p 0
\end{aligned}
\end{aligned}
$$

Dari hasil perhitungan didapatkan bahwa pada peningkatan investasi awal dibawah 600,8340525 \% PLTD masih layak dioperasikan karena nilai NPW >0 atau positif. Kemudian NPW $=0$ bila investasi awal meningkat sebesar 600,8340525 \%. Tetapi PLTD akan tidak layak dioperasikan bila pada peningkatan investasi awal diatas $600,8340525 \%$ karena nilai NPW < 0 atau NPW akan negatif. Ini artinya bahwa walaupun PLTD menaikan dana investasi sampai 600,8340525 \% PLTD tidak akan mengalami kerugian. Ini disebabkan karena kita tidak bisa memperediksi faktor looses yang terjadi akibatnya pendapatan perbulan yang didapatkan sangatlah besar yaitu $\mathrm{Rp}$ 1.456.556.911 perbulan. Sehingga itu menyebabkan walaupun kenaikan investasi awal sampai 600,8340525 \% PLTD masih layak untuk dioperasikan.

\section{Analisis sensitivitas dengan perubahan nilai pendapatan rata-rata perbulan}

Alternatif tersebut akan menjadi tidak

layak bila perubahan nilai pendapatan ratarata perbulan menyebabkan nilai NPW berubah menjadi lebih kecil dari nol. NPW akan sama dengan nol bila besarnya pendapatan adalah :

$$
\begin{aligned}
& \text { Bila pendapatan turun 85,7312\%, } \\
& \left(1-\frac{\mathbf{8 5 , 7 3 1 2 8 6 9 5}}{100}\right)=0,1427
\end{aligned}
$$

Maka didapatkan nilai $\mathrm{A}=145.655 .691 \mathrm{x}$ $0,142687131=207.831 .926$

$N P W=P+A(P / A, i \%, n)$
$=-17.478 .664 .995+207.831 .926$

(P/A, 0,6283\%, 120)

$=-17.478 .664 .995+207.831 .926$

$(84,10)$

$=-17.478 .664 .995+17.478 .664 .995$

$=$ Rp. 0

Dari hasil perhitungan didapatakan bahwa pada penurunan pendapatan kurang dari 85,73128695 \% PLTD masih layak dioperasikan karena nilai NPW $>0$ atau positif. Kemudian NPW $=0$ bila terjadi penurunan pendapatan pada $85,73128695 \%$ . Tetapi jika penurunan pendapatan lebih dari 85,73128695 \% PLTD menjadi tidak layak dioperasikan karena nilai NPW $<0$ atau negatif. Oleh karena itu PLTD tidak layak dioperasikan bila pendapatannya turun lebih dari $85,73128695 \%$.

\section{KESIMPIULAN DAN SARAN Kesimpulan}

1. Berdasarkan analisis break even point, dengan menggunakan harga jual ekonomis sebesar Rp. 2.595,064 per kWh PLTD mengalami break even point pada tahun pertama yaitu bulan ke 12 tahun 2014 , pada bulan tersebut didapatkan titik pertemuan antara total reveneu (TR) dengan total cost (TC) sebesar Rp. 515.060.118.738.

2. Dengan menggunakan harga yang disesuaikan dengan kemampuan masyarakat yaitu Rp. 800 per kWh dan dengan subsidi sebesar Rp. 29.758.612.278 perbulan PLTD akan mengalami break even point pada tahun pertama yaitu pada bulan ke 12, dimana pada bulan tersebut biaya total (TC) akan sama dengan total pendapatan (TR) yaitu sebesar Rp. 159.148.857.478.

3. Dengan menggunakan harga yang disesuaikan dengan kemampuan masyarakat yaitu Rp 900 per kWh dan dengan subsidi sebesar Rp. 28.100.809.978 perbulan PLTD akan mengalami break even point pada tahun pertama yaitu pada bulan ke 12, dimana pada bulan tersebut biaya total (TC) akan sama dengan total pendapatan (TR) yaitu sebesar Rp. 179.042.464.663.

4. Dengan menggunakan harga yang disesuaikan dengan kemampuan masyarakat dengan harga jual Rp. 1000 per $\mathrm{kWh}$ dan dengan subsidi sebesar 
Rp. 26.443.007.678 perbulan PLTD akan mengalami break even point pada tahun pertama yaitu pada bulan ke 12, dimana pada bulan tersebut biaya total (TC) akan sama dengan total pendapatan (TR) yaitu sebesar Rp. 199.936.071.847.

5. Berdasarkan analisis sensitivitas, dengan kenaikan dan penurunan investasi awal dan hasilnya menunjukan bahwa pada peningkatan investasi awal dibawah $600,8340525 \%$ PLTD masih layak dioperasikan karena nilai NPW >0 atau positif. Kemudian NPW $=0$ bila investasi awal meningkat sebesar 600,8340525 \%. Tetapi PLTD akan tidak layak dioperasikan bila pada peningkatan investasi awal diatas $600,8340525 \%$ karena nilai NPW $<0$ atau NPW akan negatif. Ini artinya bahwa walaupun PLTD menaikan dana investasi sampai 600,8340525 \% PLTD tidak akan mengalami kerugian. Ini disebabkan karena kita tidak bisa memperediksi faktor looses yang terjadi akibatnya pendapatan perbulan yang didapatkan sangatlah besar yaitu $R p$ 1.456.556.911 perbulan. Sehingga itu menyebabkan walaupun kenaikan investasi awal sampai 600,8340525\% PLTD masih layak untuk dioperasikan.

6. Dengan kenaikan dan penurunan pendapatan rata-rata perbulan, dan hasilnya menunjukan bahwa pada penurunan pendapatan kurang dari $85,73128695 \%$ PLTD masih layak dioperasikan karena nilai NPW >0 atau positif. Kemudian NPW $=0$ bila terjadi penurunan pendapatan pada 85,73128695 $\%$. Tetapi jika penurunan pendapatan lebih dari 85,73128695 \% PLTD menjadi tidak layak dioperasikan karena nilai NPW $<0$ atau negatif. Oleh karena itu PLTD tidak layak dioperasikan bila pendapatannya turun lebih dari $85,73128695 \%$.

\section{Saran}

1. Bagi mahasiswa lain yang ingin melanjutkan penelitian ini disarankan agar mencari alternatif solusi yang dapat diterapkan langsung dengan mempertimbangkan implikasi-implikasi yang akan ditimbulkan oleh alternatif yang diusulkan.

2. Bagi mahasiswa lain yang ingin melanjutkan penelitian ini disarankan agar mencari faktor-faktor yang menyebabkan looses agar didapatkan hasil yang lebih bagus.
3. Bagi instansi/pemerintahan yang terkait, penelitian ini dapat dijadikan masukan dalam mengambil langkah untuk meningkatkan kualitas serta pelayanan yang diberikan kepada konsumen dan sebagai pertimbangan pemecahan masalah.

\section{DAFTAR PUSTAKA}

Akzar R., 2012, Analisis kelayakan pengembangan usaha pengolahan gula merah tebu pada UD Julu Atia, Kecamatan Polongbangkeng Selatan, Kabupaten Takalar, Jurnal Fakultas Ekonomi Dan Manajemen Insitut Pertanian Bogor, Bogor

Anonim, 2014., PLN NTB masih alami defisist listrik, MATARAM Pos Bali.

Ariesa F.N., Tinaprilla N., 2012, Analisis kelayakan restrukturisasi mesin pabrik gula kremboong, Kabupaten Sidoarjo, Jawa Timur, Jurnal Fakultas Ekonomi Dan Manajemen Insitut Pertanian Bogor, Bogor

Bagus A.M.P., 2011, Perawatan turbocharger pada genset mesin Diesel $1380 \mathrm{KW}$, Skripsi Jurusan Teknik Mesin Fakultas Teknik Universitas Teknologi Sepuluh November, Surabaya.

Febriyandi F., 2012, Aplikasi break even point pada sistem operasional kapal motor penyeberangan Roditha PT. ASDP Indonesia Ferry (Persero) Cabang Lembar, Skripsi Jurusan Teknik Mesin Fakultas Teknik Universitas Mataram, Mataram.

Ghazali M.H., 2015, Sistem pemasukan udara menggunakan turbo-charger pada mesin Diesel New Sulzer Zav40s (Unit \#7) PLTD Ampenan, Laporan Kerja Praktek Lapangan Jurusan Teknik Mesin Fakultas Teknik Universitas Mataram, Mataram.

Halim A., Bambang S., 1990, Akuntansi Manajemen, Edisi Pertama, BPFE, Yogyakarta.

Harahap S.S., 2008, Teori Akutansi, PT Raja Grafindo Persada, Jakarta.

Himayati R., 2010, Studi kelayakan penggunaan mesin Diesel berdasarkan metode break even point (BEP) pada PLTD Labuhan Sumbawa, Skripsi Jurusan Teknik Mesin Fakultas Teknik Universitas Mataram, Mataram.

Husnan S., Suwarsono., 1999, Studi kelayakan proyek, UPP AMP YKPN, Yogyakarta.

Ibrahim Y., 2003, Studi Kelayakan Bisnis, Rineka Cipta, Jakarta. 
Kholiq M., 2015, Aplikasi break even point studi kasus: Usaha Kecil Menengah (UKM) Roti (Rotiku Rotimu) Desa Babakan, Skripsi Jurusan Teknik Mesin Fakultas Teknik Universitas Mataram, Mataram.

Komarudin, Suprijatmono D., 2012, Analisis biaya dengan menggunakan metode break even point dalam mencari volume-laba pada PT $X$, Jurnal Sainstech, Vol. 22, No. 1, Jurusan Ekonomi Fakultas Ekonomi Universitas Diponegoro, Semarang.

Nadiasa M., 2010, Analisis investasi pengembangan potensi pariwisata pada pembangunan Waduk Jehem Di Kabupaten Bangli, Jurnal IImiah Teknik Sipil Vol. 14, No. 2, Fakultas Teknik Universitas Udayana, Denpasar.

Patricia H.J., 2012, Analisis keekonomian kompleks perumahan berbasis energi sel surya (Study kasus: perumahan Cyber Orchid Town Houses Depok), Skripsi Jurusan Teknik Industri Fakultas Teknik Universitas Indonesia, Depok.

Pramono E., Sari S.P., 2012, Unjuk kerja motor Diesel tipe S-1110 dengan bahan bakar biodiesel M20 dari minyak jelantah dengan katalis 0,35\% Naoh, Jurnal Jurusan Teknik Mesin Fakultas Teknik Universitas Gunadarma.
Pujawan I.N., 2002, Ekonomi Teknik, Guna Widya, Surabaya.

Rezeki G., 2015, Analisis siklus Diesel dan sistem bahan bakar PLTD ampenan PT. PLN (Persero) Wilayah NTB Sektor Pembangkit Lombok, Laporan Kerja Praktek Lapangan Jurusan Teknik Mesin Fakultas Teknik Universitas Mataram, Mataram.

Sari K., Utomo C., 2012, Analisa pembeayaan kerjasama pemerintah dan swasta pada proyek Sidoarjo Town Square, Jurnal Vol. 1, No. 1, Jurusan Teknik Sipil Fakultas Teknik Institut Teknologi Sepuluh Nopember (ITS), Surabaya.

Sigit S., 1990, Analisa Break Even, Edisi Ketiga, BPFE, Yogyakarta.

Sudrajadinata M., 2015, Kajian tekno ekonomi unit alat pencacah plastik untuk meningkatkan nilai jual sampah plastik, Skripsi Jurusan Teknik Mesin Fakultas Teknik Universitas Mataram, Mataram.

Surjandari I., 2009, Model dinamis pengelolaan sampah untuk mengurangi beban penumpukan, Jurnal Teknik Industri, Vol. 11, No. 2, pp. 134-147 Fakultas Teknik Universitas Indonesia, Depok. 